

\section{National Operations Center of Excellence}

- Outline

- Origins (SHRP 2 and Reliability!)

- Our Vision

- NOCoE Structure

- Our Website

- Knowledge Center

- Technical Services

- Our "Ask" of You!

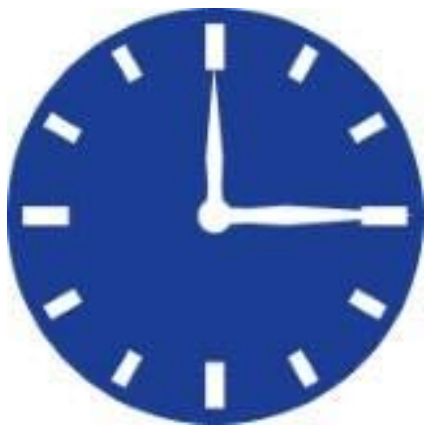




\section{KTS \\ EKTS NOCOE}

\section{Origins of NOCoE}

- SHRP 2 Reliability Research $\rightarrow$ implementation activities

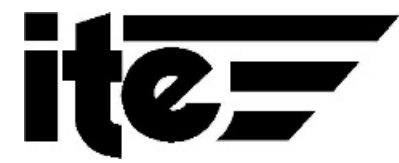

- Development of "enhanced knowledge transfer system (EKTS)

$\overline{\mathrm{AAASH}}$

- MOU between AASHTO, ITE, ITS America, and FHWA

ITS

- NTOC framework was merged into the National Operations Center of Excellence 


\section{Our Vision}

\section{Improve surface transportation}

system reliability by

lending exceptional support services to TSM\&O practitioners 


\section{NOCoE Structure}

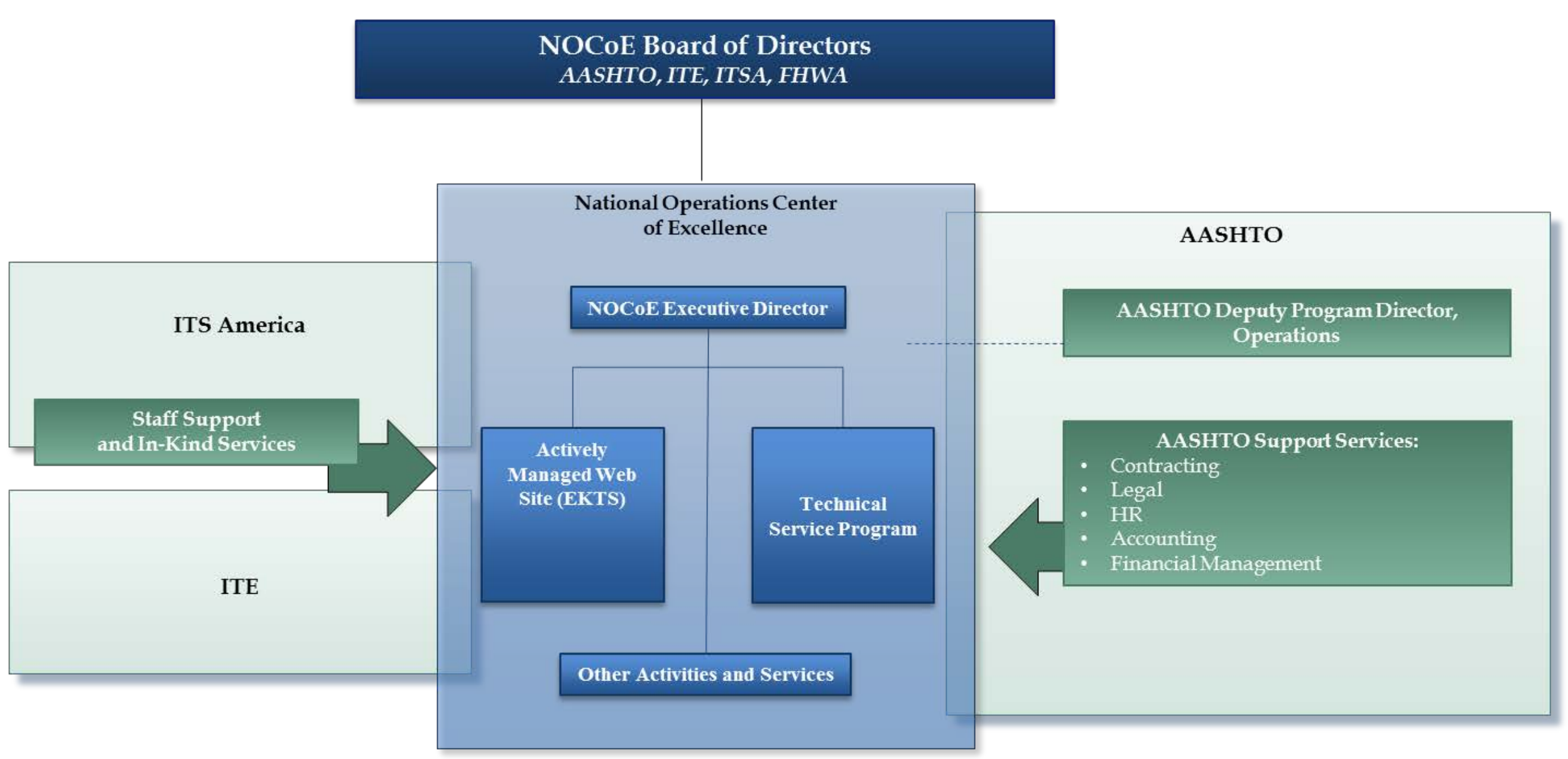



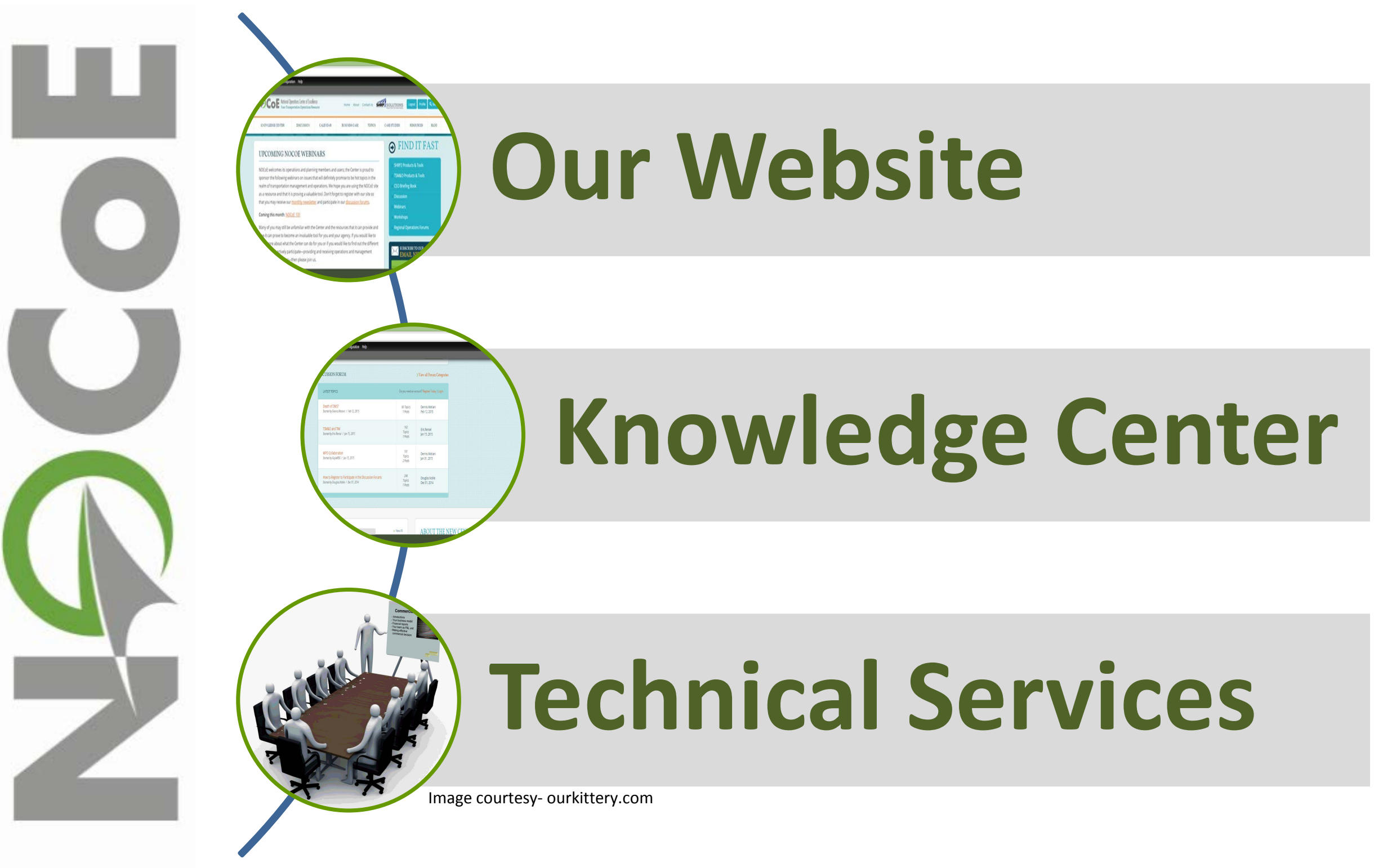


\section{www.transportationops.org}

\section{WELCOME TO THE NATIONAL OPERATIONS CENTER OF EXCELLENCE}

\section{REQUEST FOR PROPOSAL FOR NATIONAL OPERATIONS CENTER OF EXCELLENCE} MANAGING DIRECTOR

The American Association of State Highway and Transportation Officials (AASHTO) invites bidders to submit proposals to this Request for Proposals for the requested National Operations Center of Excellence (NOCOE) Managing Director with performance from no later than May 15, 2016, to December 31, 2016, and with the provision of mutual annual renewal of the resultant contract. Questions of a technical or contractual nature about the contents of this RFP are due no later than СOB February 19, 2016, to the attention of Mr. Strat Cavros, AASHTO Manager of Acquisitions, Contracts \& Business Development (Contracts Manager), at scavros@aashto.org.

AASHTO will strive to answer questions and send those answers by e-mails to prospective bidders as an Amendment to the RFP by February 29, 2016. Proposals must be sent to Mr. Cavros no later than 4:00 PM EDT March 18, 2016. It is expected that AASHTO will make an award to the successful bidder no later than April 30, 2016. Please click here for further information.

Previous

Next

\section{DISCUSSION FORUM}

$>$ View all Forum Categories
HEADLINE NEWS

- View All

SHRP2 Moving Us Forward

January 26, 2016

2016 TRB Annual Meeting: Five Webcast

Recordings Now Available

January 26,2016

Use of High-Resolution Signal Controller Data to Identify Red Light Running January 20, 2016
Headline News

Industry Developments

Upcoming Events

Center News

Most Recent Post

\section{REGIONAL OPERATIONS FORUMS}

Regional Operations Forums (ROFs), developed by the second Strategic Highway Research Program (SHRP2) and the Transportation Research Board (TRB), provide practitioners with new and innovative approaches for managing and operating the highway system, drawing from the cutting edge work being carried out under the SHRP2 program and 


\section{Knowledge Center: \\ Over 1,000 resources and counting!}

- Active Traffic Management

- Arterial Management

- Autonomous Vehicles/Connected Vehicles

- Demand Management

- Electronic Toll and Fare Collection

- Emergency Preparedness and Security

- Freeway Management

- Freight Management and Commercial Vehicle Operations

- HOV Lane Development
- Intelligent Transportation Systems

- Integrated Corridor Management

- Managed Lanes

- Regional Traffic Management Centers

- Road Weather Management

- Special Events Management

- Traffic Incident Management

- Traffic Signal Operations

- Traveler Information

- Work Zone Management 


\section{Technical Services Plan}

Virtual/Webinar Peer Exchanges

In-Person Peer Exchanges

Assist agencies in conducting CMM Self-evaluations

Maintain TSM\&O research report library/reference, maintain status of ongoing/active research activity

Webinar Training

National Annual TSM\&O Summit 


\section{Year 1: Technical Services Highlights}

- Peer Exchanges (5 + this workshop)

- Seattle, Tennessee, Arizona Traffic Incident Management

- Northeast and Pacific Northwest Regional Exchanges

- Webinars (over 20)

- CMM Dimensions

- Implementing ICM

- Seattle TIM Lessons Learned

- Virtual Peer Exchanges

- Special events (RNC in Cleveland)

- Decision Support Systems (DSS)

- National Summit on TSM\&O Workforce Development 


\section{Our Ask of You!}

1. Register!

2. Share with others

3. Provide feedback

4. Add the NOCoE logo/link to your website.

5. Suggest new technical services

6. Share your own material!

Thomas E. Kern Managing Director tkern@transportationops.org
Steven M. Lavrenz

Technical Services Manager slavrenz@transportationops.org 